\title{
Allogeneic CMV/AdV-Specific Cytotoxic T Lymphocytes
}

National Cancer Institute

\section{Source}

National Cancer Institute. Allogeneic CMV/AdV-Specific Cytotoxic T Lymphocytes. NCI

Thesaurus. Code C88310.

A population of allogeneic cytotoxic T lymphocytes (CT LS) specifically reactive to cytomegalovirus (CMV) and adenovirus (AdV) with potential antiviral activity. Allogeneic CMV/AdV-specific cytotoxic T lymphocytes are prepared by exposing donor-derived CT LS to a lethally irradiated Epstein-Barr virus-positive lymphoblastoid B cell line (EBV-LCL) that has been transduced with a clinical-grade adenoviral vector (Ad5f35CMVpp65) as a source of CMV and AdV antigens. Infusion of these CT Ls into stem cell transplant recipients may prevent CMV and AdV viral disease. 